\title{
EXPERIMENTAL AND THEORETICAL ASPECTS REGARDING DESIGN AND TESTING OF THERMOBARIC MUNITIONS FOR RECOILLESS ARMAMENT SYSTEMS
}

\author{
Ovidiu-George IORGA*, Mihail MUNTEANU**, Tudor-Viorel ȚIGĂNESCU***, \\ Gabriel EPURE*
*Scientific Research Center for CBRN Defense and Ecology, Bucharest, Romania **Military Technical Academy, Bucharest, Romania
***Military Equipment and Technologies Research Agency, Bucharest, Romania ovidiu.iorga@nbce.ro

\begin{abstract}
The purpose of this paper is to present theoretical and experimental aspects regarding the design and testing of a thermobaric unguided fin-stabilized reactive projectile destined to be fired from a recoilless smoothbore gun, namely the anti-tank grenade launcher SPG-9 (AG-9). Some theoretical aspects regarding thermobaric explosive mechanism are presented and experimental determinations are made considering the relation between the explosive core and the overall calibre of the munition. The interior and exterior ballistics of the munitions are estimated by mathematical models and the results are validated through experimental firings with the prototype munition. The destructive effect of the munition is estimated by real firings against buildings and structures.
\end{abstract}

Keywords: thermobaric, grenade, recoilless

\section{Introduction}

The experience of the latest military conflicts has shown the urban area as a space for combat. New types of asymmetric conflicts as well as global urbanization will require the transformation of combat tactics and, implicitly, weaponry used to wage fighting in urban areas.

The urban area is dominated by buildings and structures with solid reinforced concrete structure [1-3]. These spaces are real shelters for the insurgent elements present in the battlefield. Experience in the latest conflicts (Afghanistan, Syria) has demonstrated the major destructive effect caused by small groups of enemies housed in or near buildings. The existence of both snipers and anti-tank missile launchers in these areas can lead to serious losses among our own troops. At the same time, the neutralization of such targets proves to be extremely difficult due to the high degree of shelter. To help eliminate the risks and threats specific to the enemy in urban guerrilla formations it is necessary to equip combat units with weapon systems capable of neutralizing the enemy forces housed in buildings, buried shelters, bunkers, tunnels or leading to the destruction of these structures [4-6].

Thermobaric weapons are part of the airdispersed explosive systems family, known as "volumetric weapons". This family includes both fuel-air-explosive (FAE) and thermobaric explosive systems. The term used for naming this class of explosives originates from the Greek words "therme" and "baros", meaning "temperature" and 
"pressure", referring to the main destruction mechanisms for the operation of this type of weaponry [7].

The destructive characteristics of these types of weapons are based on incendiary ability and shock wave. Both thermobaric and FAE systems are based on the same functional principle [8].

Generally, a thermobaric device is composed of a high power explosive center sheath and a fuel composition axially spaced from this sheath. Consequently, the detonation of a thermobaric device produces a dual effect: [9] anaerobic detonation (no oxygen being provided from air) of the high explosive shell and [10] the aerobic post-combustion of the fuel by dissolving and mixing it with the surrounding oxygen. When a projectile containing fuel in the form of gas, liquid (aerosol) or powder explodes, a cloud dispersion takes place. Its operation is not conditioned by the existence of oxidative species in the molecule $[9,11,12]$.

By mixing with atmospheric oxygen, detonation takes place, forming a sustained shock wave and sustained propagation in all directions.

In thermobaric devices, the fuel is a mixture of mono-propellant and energetic particles. In operation, the dispersion of the mono-propellant in the air produces detonation in terms of time similar to those of conventional explosives while the energetic particles continue to burn for a longer duration, maintaining the pressure wave by keeping the detonation products (gasses) at a very high temperature.

Although the absolute value of the overpressure is lower than that of the detonation of the condensed explosives, due to the explosive transformation mechanism by deflagration, the diffusion of the fuel mixture into the surrounding space leads to a sustained mechanical and thermal impulse with considerable damage to the living targets and material [13]. The explosion of a thermobaric device consumes the oxygen from the surrounding atmosphere. In contrast to the general belief, the lethal effect is less caused by lack of oxygen but rather due to the broncho-trauma caused by the negative pressure occurring after the overpressure in the positive phase. Thermobaric weapons contain an organic mono-propellant or high-explosive fuel enriched with $\mathrm{B}, \mathrm{Al}, \mathrm{Si}, \mathrm{Ti}, \mathrm{Zr}$ or $\mathrm{C}$ energetic particles. The first industrialized ammunition based on the thermobaric system was RPO-A of Russian production. The thermobaric charge consisted of a mixture of magnesium $(\mathrm{Mg})$ and isopropyl nitrate (IPN). This simple recipe leads to an explosion with devastating pressure wave, especially against shelters [14].

Unlike thermobaric explosives, the shock wave generated by a conventional explosive has a localized manifestation and substantially decreases with distance. Consequently, conventional explosives have limited effect on targets hidden in bunkers or shelters.

Recently, thermobaric explosive systems (TBX) based mainly on metallic powders have been optimized to support postcombustion, which is the heat generator and the pressure wave. During detonation, highexplosives such as 2,4,6-trinitrotoluene (TNT), cyclo-1,3,5-trimethylene-2,4,6trinitramine (RDX), pentaerythritoltetranitrate (PETN) or cyclotetramethylenetetranitramine (HMX) generate shock waves of short duration but high intensity, being destined for fragment propulsion, destruction by shattering mechanism or penetration of armored structures. However, the lethal effect of these explosives occurs only in their vicinity, with a limited use in the destruction of fortifications and structures. In order to diminish these shortcomings, weapons with combined effect were developed, capable of generating shock waves and increased impulse for the purpose of destroying the targets housed in tunnels, beneath fortified walls and shelters. 


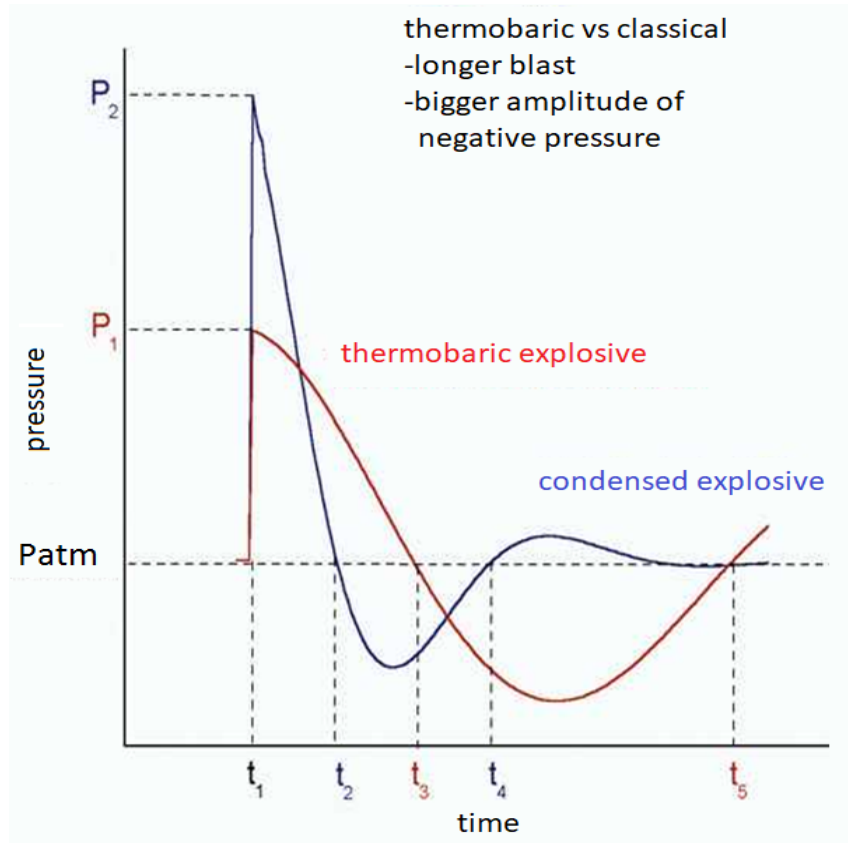

Figure 1: The overpressure profile in the shock wave front of a thermobaric explosive compared to a conventional explosive

\section{Calculations}

Thermobaric grenade for grenade launcher AG-9 (TBG-9) is intended for:

- destroying or removing the enemy from the battleground in open ground or in campaign fortification works or embarked on unarmored or lightly armored vehicles;

- the destruction or damage of unarmored or light-armored vehicles, groundstationed aircrafts, rocket launching systems, radiolocation and radio communication antennas;

- destruction or damage to wood, brick or concrete buildings, fuel tanks, deposits;

- fighting in the city against resistance points or isolated shooters.

The TBG-9 warhead works on the basis of an unconventional explosive (the mixture of a combustible substance and atmospheric air) and acts on the target by shock, fire, and shrapnel. The TBG-9 munition completes the AG-9 grenade launcher fire unit with a modern and very efficient shot. The main performance features of the product are:

- - direct sight distance $800 \mathrm{~m}$;
- - maximum range .......... 1000 - 1500 m;

- - direct hit range $400 \mathrm{~m}$;

- - Precision at direct sight distance:

- - range $<1.5 \mathrm{~m}$;

- - direction $<1 \mathrm{~m}$;

- - effect over living targets:

- -lethal effect $8 \mathrm{~m}$

- -incapacitating $10-15 \mathrm{~m}$

Physical characteristics:

- calibre $73 \mathrm{~mm}$;

- payload mass... $1.54 \mathrm{~kg}$

- warhead mass $4,25 \mathrm{~kg}$;

- Operating temperature range $-19^{\circ} \mathrm{C}$ to $+49^{\circ} \mathrm{C}$.

\subsection{Design of the warhead}

In the experimental research we have proposed the design of a thermobaric projectile that can be used together with the AG-9 grenade launcher, without bringing it constructive changes. This approach assumed the following design conditions:

- A thermobaric grenade built to be used in conjunction with the existing armament system, which is why the use of the rocket engine, stabilizer and 
shotgun used in the PG-9 anti-tank grenade has been adopted.

- The newly designed ballistic features of the newly projected strike to not fundamentally differ from basic ammunition to avoid destabilizing the stroke or to print loads above the safety limit of the AG-9 gun;
- Designing a warhead so that it has a useful volume of $1.5 \mathrm{~kg}$ of thermobaric mixture, respecting the optimal configuration but not exceeding $73 \mathrm{~mm}$, the size of the thrower - assimilation of M6-R impact fuse from the OG-7.

Table 1 Characteristics of the thermo-barric TBG9 and basic PG-9

\begin{tabular}{|c|c|c|}
\hline Feature & PG9 & TBG9 \\
\hline Total mass & $2530 \mathrm{~g}$ & $4250 \mathrm{~g}$ \\
\hline Grenade mass with fuze & $1200 \mathrm{~g}$ & $2955 \mathrm{~g}$ \\
\hline Caliber & $73 \mathrm{~mm}$ & $73 \mathrm{~mm}$ \\
\hline $\begin{array}{c}\text { Grenade length } \\
\text { Length without propellant } \\
\text { charge }\end{array}$ & $380 \mathrm{~mm}$ & $488 \mathrm{~mm}$ \\
\hline $\begin{array}{c}\text { Initial velocity } \\
\text { Position of center of mass } \\
\text { by the base }\end{array}$ & $370 \mathrm{~m} / \mathrm{s}$ & $311 \mathrm{~m} / \mathrm{s}$ \\
\hline $\begin{array}{c}\text { Shape index } \\
\mathrm{i}:=\frac{2}{\mathrm{n}} \cdot \sqrt{\frac{4 \mathrm{n}-1}{\mathrm{n}}}\end{array}$ & $445 \mathrm{~mm}$ \\
\hline $\begin{array}{c}\text { Ballistic coefficient } \\
\text { BC }:=\frac{\mathrm{m}}{\mathrm{i} \cdot \mathrm{d}}\end{array}$ & 2.11 & 0.34 \\
& & \\
\hline
\end{tabular}

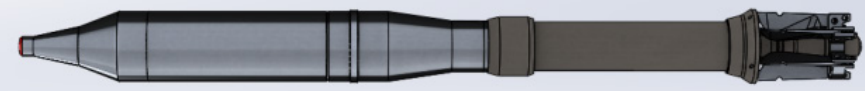

Figure 2: Thermobaric grenade -overview

In order to determine the internal configuration of the thermobaric grenade for AG-9, the explosive performances (the value of the overpressure in the shock wave, the impulse and the duration of the explosion) were evaluated for experimental configurations of cylindrical shape with fixed outer diameter and variable diameter sheath. 
Table 2 Internal configuration for experimental thermobaric device

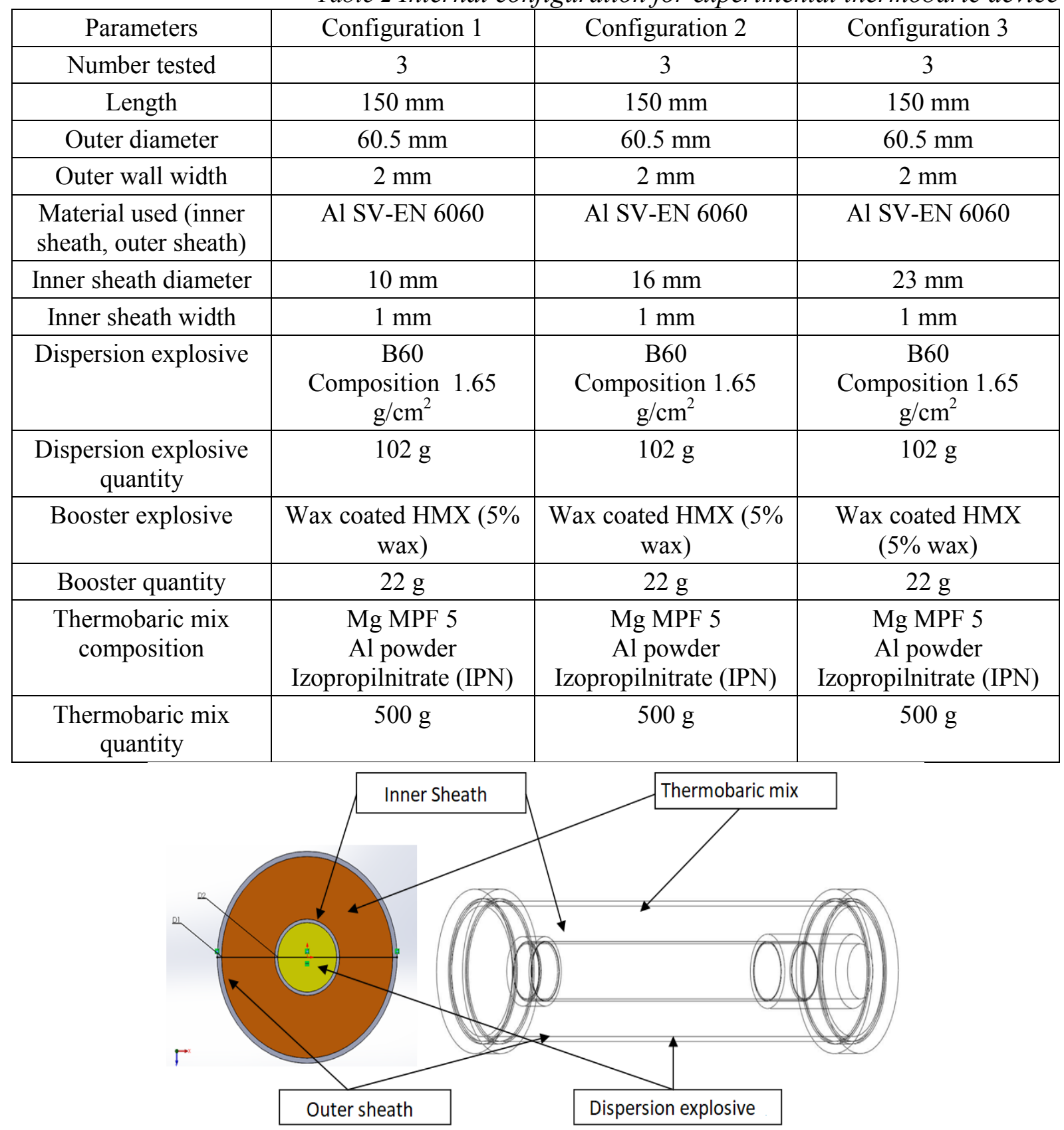

Figure 3: Internal configuration of experimental devices

\subsection{Interior ballistics}

The theory of interior ballistics provides the bases for the calculation of pressure within the gun and projectile velocity as functions of projectile displacement.

The following assumptions are made in order to simplify the model

The propellant burns after a law proportional to the pressure;
The initial force required to move will be represented by a start pressure;

The nozzle flow can be described in terms of a quasi-static flow;

There is no loss of unburnt propellant through the nozzle during the burning period.

During the burning of the propellant, when the nozzle is open and theround is in 
motion, the following equations describe the case:

$\mathrm{p}\left(\mathrm{K}_{0}+\mathrm{Ax}-\frac{\mathrm{C}}{\delta}\right)=\operatorname{CNRT}\left(1+\frac{\mathrm{kCN}}{6 \mathrm{~W}}\right)$

$\mathrm{W}_{1} \frac{\mathrm{d}^{2} \mathrm{x}}{\mathrm{dt}^{2}}=\mathrm{Ap}$

$\mathrm{W}_{1}=\mathrm{W}+\frac{1}{2} \mathrm{kCN}$

$\mathrm{D} \frac{\mathrm{df}}{\mathrm{dt}}=-\beta \mathrm{P}^{\alpha}$

$\phi=(1-f)(1+\theta f)$

$\frac{\mathrm{dN}}{\mathrm{dt}}=\frac{\mathrm{d} \phi}{\mathrm{dt}}-\frac{\psi \mathrm{SP}}{\mathrm{C}(\mathrm{RT})^{1 / 2}}$

$\frac{\mathrm{d}(\mathrm{NT})}{\mathrm{dt}}=-(\gamma-1) \frac{\mathrm{AP}}{\mathrm{CR}} \frac{\mathrm{dx}}{\mathrm{dt}}+\mathrm{T}_{0} \frac{\mathrm{d} \phi}{\mathrm{dt}}-$ $\frac{\gamma \psi \mathrm{SP}(\mathrm{RT})^{1 / 2}}{\mathrm{CR}}$

$\mathrm{S}$ - the area of the nozzle

A -bore area

$\phi$ - fraction of burnt propellant

$\gamma-1 / \phi+1$, dimensionless

$\psi$ - the fraction of burnt propellant

W-the mass of the round

$\mathrm{W}_{1^{-}}$corrected mass, taking into consideration the products which flow through the nozzle

$\mathrm{CN}$ - mass of gas present in the gun

$\theta$ - the form factor of the grain

Special cases and periods of time can be derived from this set of equations. For example, before the nozzle opens, we can simply consider the area $\mathrm{S}$ to be 0 ; before the round starts to move, $\frac{d x}{d t}=0$. After the propellant burns completely, $\phi=1$. These equations are different from the ones used to describe conventional, non-leaking guns for several reasons. This is due mainly to the fact that one must take into consideration the loss of energy which appears because of the gas-flow through the nozzle. Of course, by the same reason appears the necessity for a new equation, which describes the flow through the nozzle, giving the rate at which burning products are evacuated.
Peak pressure is a significant design parameter affecting blast and flash.The larger the piezometric efficiency, the shorter the travel required for a given muzzle energy. Hence, an important consideration in the determination of the propellant charge is the maximizing of the area defined by the pressure-travel relationship, while attempting to minimize peak pressure.

By means of numerical integration, the problem is put in a straightforward way. A convenient form of these equations is where all parameters are expressed in terms of dimensionless variables. Thus we write:

$\mathrm{x}=\mathrm{l} \xi$

$\mathrm{l}=\frac{\mathrm{U}-\frac{\mathrm{C}}{\delta}}{\mathrm{A}}$

$\mathrm{S}=\mu \mathrm{A}$

$\mathrm{t}=\frac{\mathrm{ADl}}{\beta \mathrm{CRT} \mathrm{T}_{0}} \tau$

$V=\frac{B R C T_{0}}{A D} \frac{d \xi}{d \tau}$

$\mathrm{T}=\mathrm{T}_{0} \mathrm{~T}$

$P(t)=\frac{\mathrm{CRT}_{0} \pi(\tau)}{U-\frac{C}{\delta}}$

$\mathrm{M}=\frac{\mathrm{A}^{2} \mathrm{D}^{2}}{\beta^{2} \mathrm{WCR} \mathrm{T}_{0}}$

$\Psi=\frac{\psi \mathrm{SD} 0}{\beta \mathrm{C}\left(\mathrm{RT}_{0}\right)^{1 / 2}}$

And thus the set of equations becomes:

$$
\begin{aligned}
& \pi(1+\xi)=\mathrm{NT}^{\prime}\left(1+\frac{\mathrm{kCN}}{6 \mathrm{~W}}\right) \\
& \frac{\mathrm{d}^{2} \xi}{\mathrm{d} \tau^{2}}=\frac{\mathrm{M} \pi}{1+\frac{\mathrm{kCN}}{2 \mathrm{~W}}} \\
& \mathrm{~W}_{1}=\mathrm{W}+\frac{1}{2} \mathrm{kCN} \\
& \frac{\mathrm{df}}{\mathrm{d} \tau}=-\left(\frac{\mathrm{CRT}_{0}}{\mathrm{Al}}\right)^{\alpha-1} \pi^{\alpha} \\
& \phi=(1-\mathrm{f})(1+\theta \mathrm{f}) \\
& \frac{\mathrm{dN}}{\mathrm{dt}}=\frac{\mathrm{d} \phi}{\mathrm{d} \tau}-\Psi \pi\left(\mathrm{T}^{\prime}\right)^{-1 / 2} \\
& \frac{\mathrm{d}\left(\mathrm{NT}^{\prime}\right)}{\mathrm{d} \tau}=-(\gamma-1) \pi \frac{\mathrm{d} \xi}{\mathrm{d} \tau}+\frac{\mathrm{d} \phi}{\mathrm{d} \tau}-\gamma \psi \pi\left(\mathrm{T}^{\prime}\right)^{1 / 2}
\end{aligned}
$$


These equations are easily solved by numerical integration, in increments of $\tau$

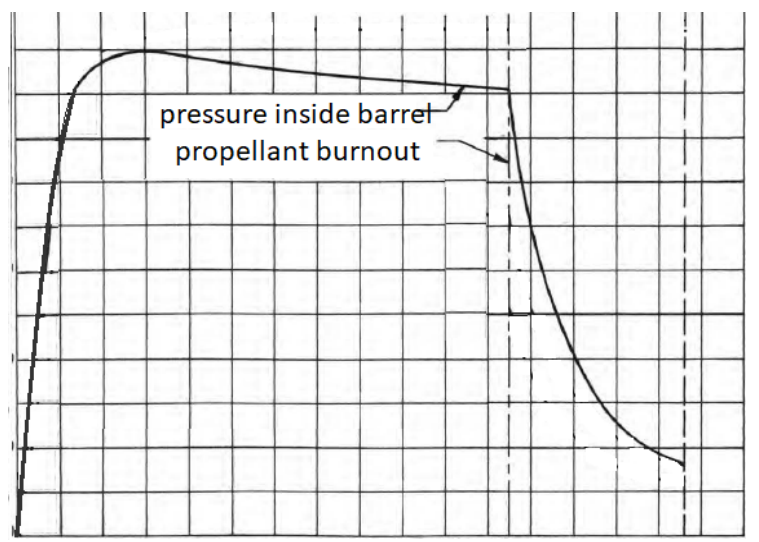

Figure 4: Pressure-time curve

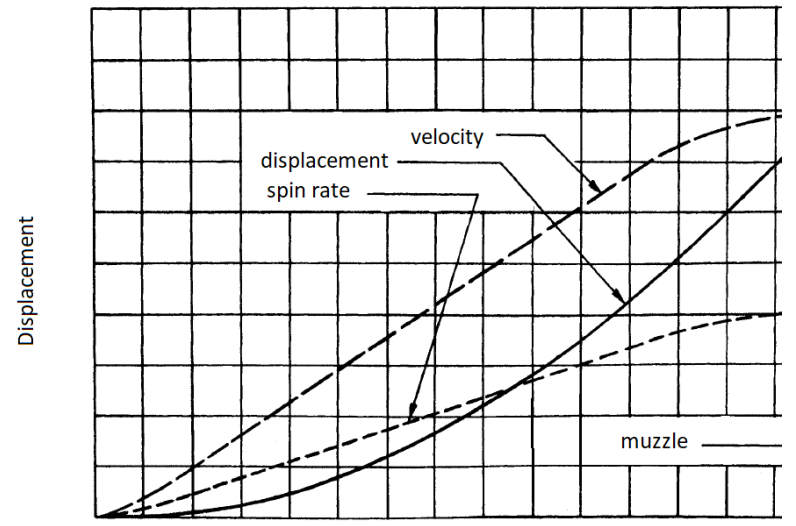

Figure 5: Displacement, velocityand spin rate evolution from a classical gun, more pronounced in the period after the burnout of the propellant, in the adiabatic expansion period. The pressure falls rapidly, for there are also losses through the nozzle.

\section{Experimental}

\subsection{Determination of initial velocity and maximum velocity}

To determine the initial velocity and the maximum velocity, experimental firings with a number of 14 tries were performed, the speeds being determined by the Doppler radar. The data obtained are illustrated in Table 3. There is a significant decrease in the initial and maximum velocity compared to the antitank round. This may have a negative influence on the ballistic behavior on the trajectory.

The shape of the pressure curve differs

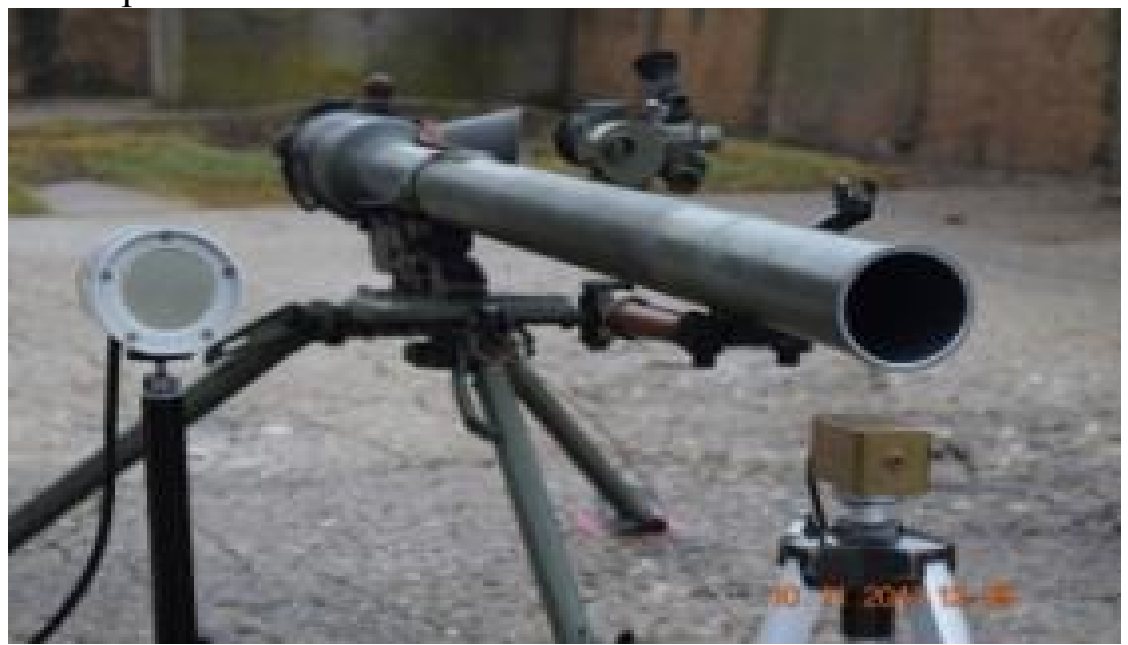

Figure 5: The loaded launcher and the setup of the doppler radar 

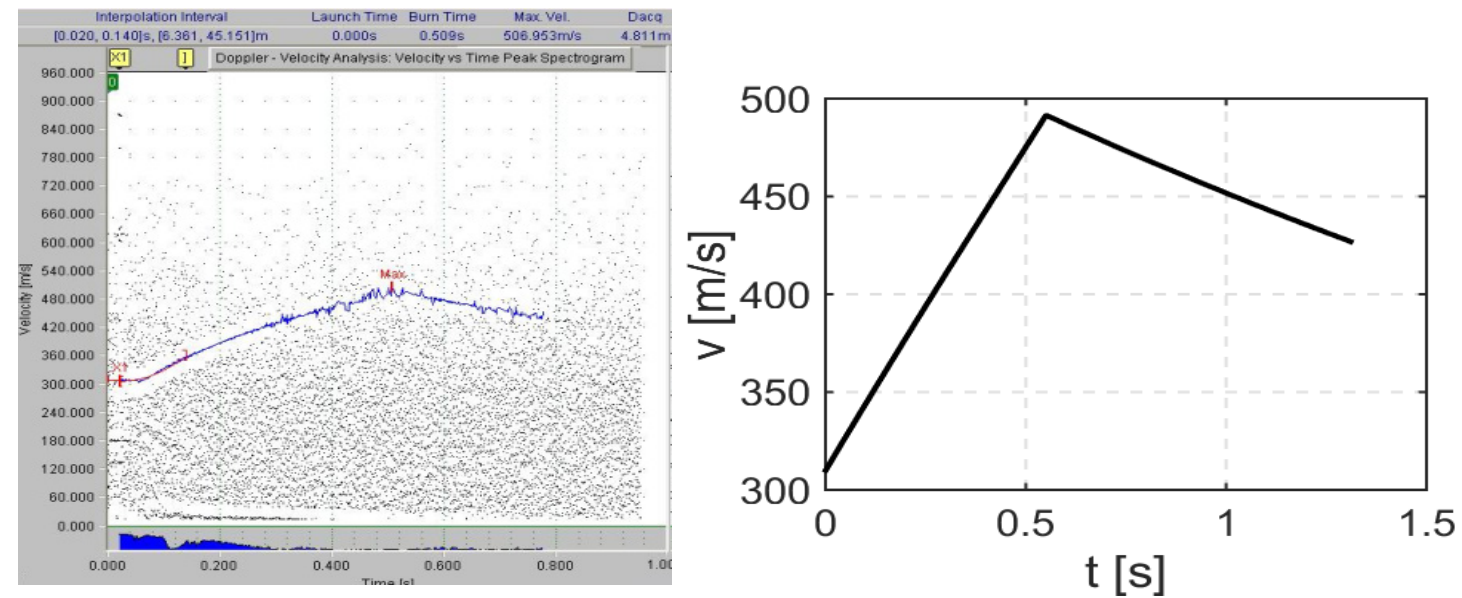

Figure 6: Velocity profile of the thermobaric round (experimental-left, theoretical-right)

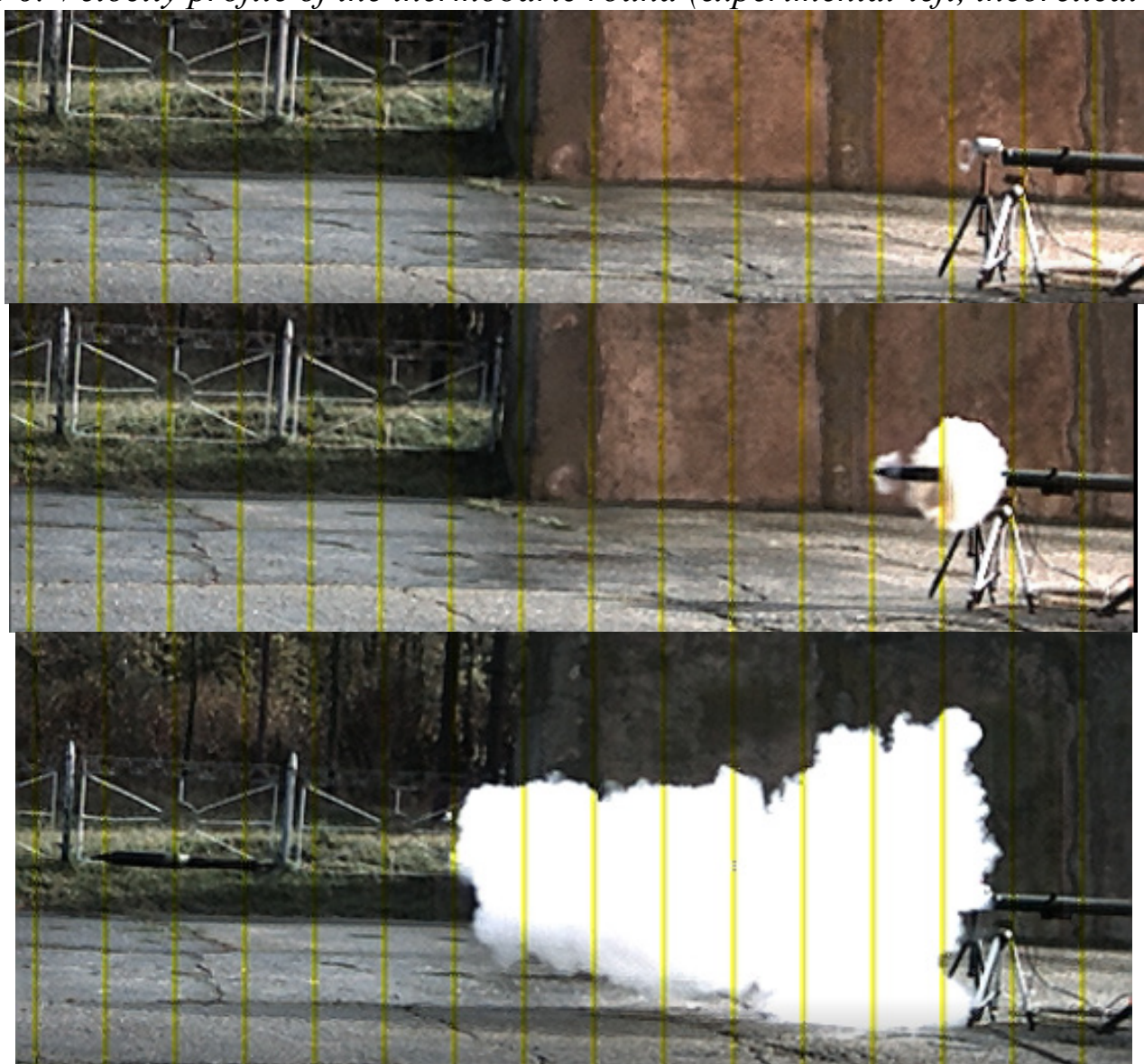

Figure 7: Thermobaric round leaving the muzzle

Table 3 Initial velocity and maximum velocity of the thermobaric round

\begin{tabular}{llllllllllllllllll}
\hline No of test & 2 & 3 & 4 & 5 & 6 & 7 & 8 & 9 & 10 & 11 & 14 & 17 & 18 & 19 & $\begin{array}{c}\text { Med PG- } \\
9\end{array}$ \\
\hline $\begin{array}{l}\text { Initial } \\
\text { velocity }\end{array}$ & 311 & 316 & 315 & 310 & 313 & 312 & 312 & 308 & 307 & 317 & 308 & 306 & 309 & 307 & 311 & 370 \\
$\begin{array}{l}\text { Maximum } \\
\text { velocity }\end{array}$ & 507 & 502 & 499 & 501 & 493 & 489 & 493 & 503 & 498 & 495 & 496 & 496 & 490 & 489 & 497 & 570 \\
\hline
\end{tabular}




\subsection{Determination of firing parameters and precision}

Determination of the elevation angle and precision when shooting at a distance of $200 \mathrm{~m}$. In order to determine the elevation angle and the shooting precision at a distance of 200 meters, experimental shootings with thermobaric rounds were made under the following conditions:

- Series 1: Thermobaric rounds, 10 pieces

- Height of target: $2 \mathrm{~m}$

- Angle of elevation: $1^{\circ}$

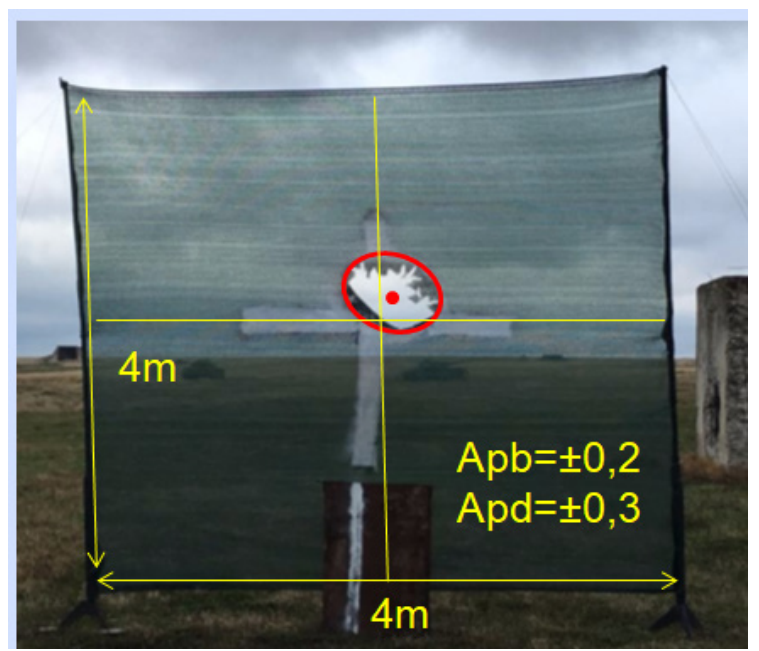

Figure 8: Target shooting accuracy at $200 \mathrm{~m}$ of the 10 round series

Although the thermobaric stroke is $70 \%$ heavier than the antitank hit, it has a satisfactory precision.

\subsection{Determination of destruction capacity of the thermobaric round by means of experimental shootings}

For the determination of destruction capacity, experimental firings were made on two targets. This determination is not objective and precise, but provides valuable insights into the concrete operational destination to which this type of ammunition can respond.

Target no. 1: Building of BCA type bricks of $3 \times 2 \times 2,2 \mathrm{~m}$ dimensions. The results of the tests are illustrated in the following figure:

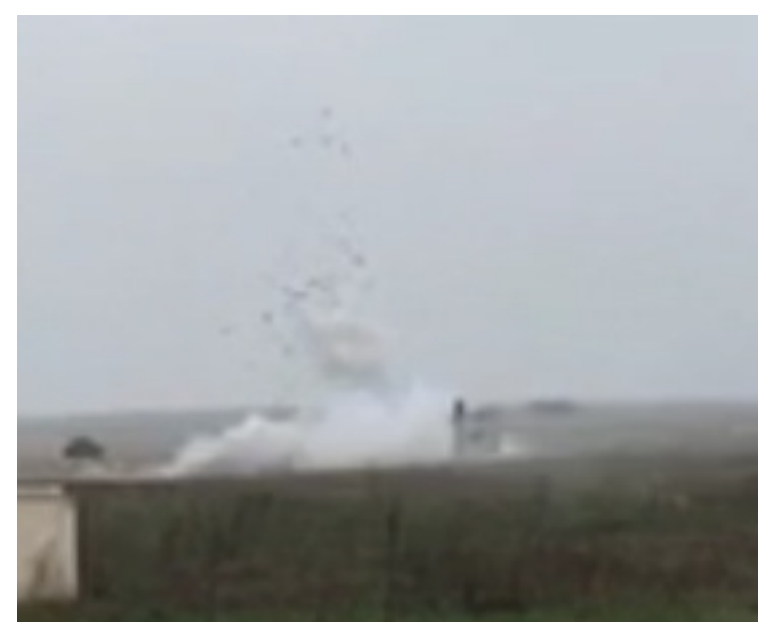

Figure 9: The destructive effect of the thermobaric round on a building

Target no. 2: storage consisting of 12 empty steel barrels of 200L. The results of the tests are illustrated in the following figure:

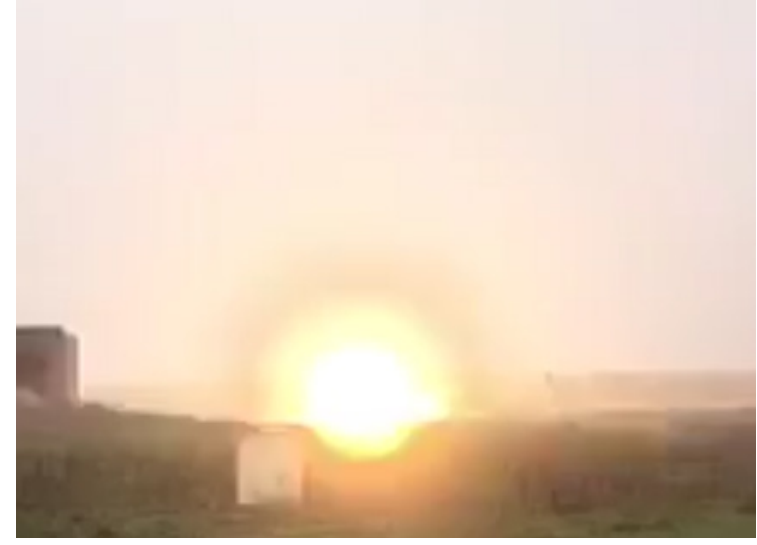

Figure 9: The destructive effect of the thermobaric round on a storage

\section{Conclusions}

This work aimed to determine the opportunity and the possibility of designing a thermobaric round for the AG-9 grenade launcher. After the study, the following conclusions can be drawn:

- Thermobaric explosion involves a phase of dispersion and initiation of a supracarbonated fuel mixture in the surrounding atmosphere. This type of explosion can be done using an explosive sheath for dispersion surrounded by a thermobaric mixture.

- Composition of thermobaric mixtures varies depending on the effect that is sought. For ternary mixtures of the AlMg-IPN type it has been established the 
optimum ratio of mass between these components.

The round can be accomplished by assimilating the rocket engine and the PG-9 propelling charge. The round is equipped with the M6-Rfuze, coming from the explosive round OG-7.

- The round has a 70\% bigger total mass, which reflects on the initial and maximum velocity.

- The round is stable on the trajectory, which is also reflected in the high accuracy at the shootings at $200 \mathrm{~m}$ and $300 \mathrm{~m}$.

- The destructive effect is the one expected, the round being able to completely destroy buildings of brick and metal structures.

\section{Acknowledgements}

This work has been done within the sectorial research plan of the Ministry of Defense. We acknowledge the support given by the Joint Logistic Command in the experimental determinations.

\section{References}

[1] Prada M.F., Popescu D.E., Bungau C., Building Education, Source of Energy Saving in Romania, the 15th National Technical-Scientific Conference on Modern Technologies for the 3rd Millennium, Conference Proceedings, pp. 157-162, Oradea, Romania, 2016.

[2] Prada, M., Popescu, D.E., Bungau, C., Pancu, R., Bungau, C., Journal of Environmental Protection and Ecology, Vol. 18, No. 3, pp. 1146-1157, 2017.

[3] Vesselenyi T., Bungau C., Husi G., Research Equipment and Computation Techniques for Intelligent Building Applications, International Symposium on System Integration, Conference Proceedings IEEE/SICE, pp. 228-233, Tokyo, Japan, 2014.

[4] Sfarlog B., Bârsan G., Moşteanu D., Constantin D., The viability and effectiveness of modern models of leadership in the military organization. formative implicationsn, Proceedings of the 9th international management conference: Management and innovation for competitive advantage, Book Series: International Management Conference, pp.67-73, Bucharest, Romania, 2015.

[5] Sfarlog B., Bârsan G., Moşteanu D.E., Bădilă M, Sustainability of Wics Model in Military Leadership, Proceedings Of The 10th International Management Conference Challenges of Modern Management, pp. 393-400, Bucharest, Romania, November 2016.

[6] Mosteanu D., Halmaghi, E.E., The challenges of sustainable development, 18th International Conference - The Knowledge-Based Organization: Management and Military Sciences, Conference Proceedings 1, pp. 548-552, Sibiu, Romania, 2012.

[7] Iosif G., Epure G., Anghel L., Moșteanu D., Numerical Modelling of Terminal Ballistic for $40 \times 46 \mathrm{~mm}$ Lesslethal Kinetic Grenade, The $23{ }^{\text {th }}$ International Conference Knowledge Based Organization, "Nicolae Bălcescu" Land Forces Academy, published Online: 2017-07-22, DOI: https://doi.org/10.1515/kbo-2017-0176.

[8] Bîrsan G., Giurgiu L., Moşteanu D., An Innovative Autofrettage Process for Increasing Life Cycle and Performances of Gun Barrels, EUROMOT 2008-The third European Conference of Technology, Organized by CERAM Buisiness School, September 17-19 Nice, France, 2008.

[9] Iorga O. G., Orban O., Țigănescu T. V., Voicu A. E., Lupoae M., Eftimie B. I., , MTA Review, Vol. XXVII, No. 6, 2017.

[10] Iorga O, Matache L., Epure G., Rotariu A., Tiganescu V., Rotariu T., Experimental Techniqes for Measuring Overpressure Generated by Thermobaric Devices, 19th International seminar New trends in research of energetic materials, Pardubice, Czech Republic, 20-22 April, 2016. 
[11] Carac, A., Boscencu, R., Carac, G., Bungau, S.G., Revista de Chimie - Bucharest, Vol. 68, No. 10, pp. 2265-2269, 2017.

[12] Carac, A., Boscencu, R., Dediu, A.V., Bungau, S.G., Dinica, R. M., Revista de ChimieBucharest, Vol. 68, No. 7, pp. 1423-1428, 2017.

[13] Iorga O., Matache L., Petrea N., Orban O., Tiganescu T. V., Rotariu T., Theoretical and experimental aspects regarding aero-dispersed explosive systems, Greener and Safer Energetic and Ballistic Systems International Conference, Bucharest, 26-27 May, 2016.

[14] Terzić S., Kolundžija M. D., Azdejković M., Minov G., Scientific Technical Review, Vol. LIV, No. 3-4, pp. 24-27, 2004. 